\title{
MODELOS DE DIVERSAS FIDELIDADES NO PROCESSO DE DESIGN ITERATIVO
}

\author{
Ana Veronica Pazmino Dra. \\ Universidade Federal de Santa Catarina UFSC \\ ana.veronica@ufsc.br \\ Regiane Pupo Dra. \\ Universidade Federal de Santa Catarina UFSC \\ regiane.pupo@ufsc.br \\ Ivan Medeiros Msc. \\ Universidade Federal de Santa Catarina UFSC \\ ivan.medeiros@ufsc.br
}

\begin{abstract}
Resumo: O artigo mostra a fundamentação teórica sobre modelos de diversas fidelidades como ferramentas de teste e avaliação no processo de design iterativo. $O$ trabalho também apresenta uma descrição dos tipos de modelos utilizados no design de produto, as vantagens do uso para a equipe de projeto e as informações que podem ser coletadas para o aperfeiçoamento dos projetos. Finalmente é mostrado um exemplo prático de construção de um modelo de baixa fidelidade de um veículo ultra compacto utilizando novas tecnologias. Dessa forma, o artigo defende o uso da prototipagem ao longo do processo projetual como fornecedor de insights para o designer.
\end{abstract}

Palavras-chave: Design iterativo, prototipagem, design de produto.

\begin{abstract}
This paper illustrates the theoretical background about several level of models, as testing and evaluation tools during iterative design processes. This work also presents a description of different kinds of models, common used in product design, their advantages for the design team and the information that can be collected aiming project improvement. Finally, a practical example of the construction of an ultra impact vehicle model, using new technologies is shown. Thus, this paper endorses the use of rapid prototyping tools throughout the design process as an insight giver to the designer.
\end{abstract}

Key-words: Iterative design, prototyping, product design 


\section{INTRODUÇÃO}

Para a realização de um projeto centrado no usuário devem-se utilizar algumas ferramentas capazes de fornecer parâmetros úteis para o desenvolvimento de produtos e ou ambientes adequados ao uso. Neste trabalho apresentam-se a prototipação de diversas fidelidades como ferramenta que auxilia a atividade projetual do designer. $O$ artigo defende que um projeto centrado no usuário deve ser iterativo, ou seja, um processo de design baseado em um modelo cíclico que envolve protótipos, testes, análise e aperfeiçoamento contínuo. No projeto iterativo, a interação do usuário com o produto projetado é usado como uma forma de pesquisa cujo output é informação que provoca a evolução de um projeto com versões sucessivas de iterações.

Será apresentada uma pesquisa documental de protejo iterativo, mostrando a importância de ferramentas como manequins antropométricos e os modelos ou mockups como meios para aperfeiçoar as tomadas de decisão em um projeto de design. $\mathrm{E}$ alguns exemplos de modelos de diversas fidelidades contribuindo com as tomadas de decisão no processo projetual.

\section{DESENVOLVIMENTO}

Para Laurel (2003), testar, analisar, aperfeiçoar e repetir a ação é necessário porque a experiência de um usuário não pode nunca ser totalmente prevista e, em um processo iterativo, as decisões de design são baseadas na experiência com o protótipo. Para a autora, o protótipo é testado, as revisões são feitas e o projeto é testado mais uma vez. Desta forma, o projeto se desenvolve por meio de um diálogo permanente entre os designers, o projeto e o público. A figura 1 mostra esquematicamente 0 processo iterativo.

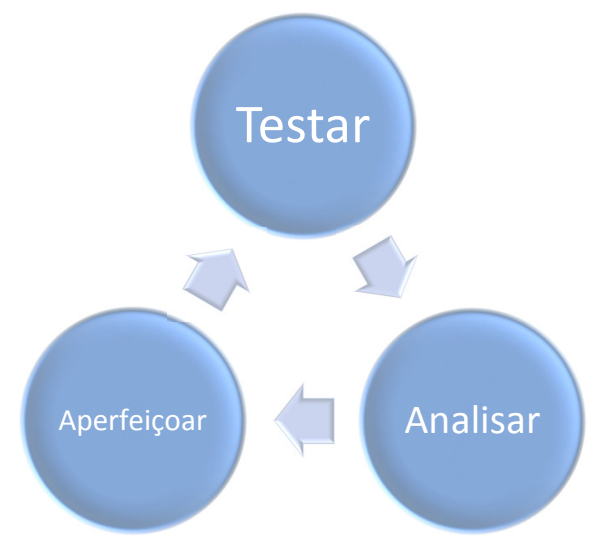

Figura 1 - Processo de design iterativo Adaptado de Laurel (2003, p. 177)

Um processo de concepção mais iterativo tende a obter um produto final mais forte e bem-sucedido. Uma forma de analisar as soluções considerando os usuários, mas não os tendo para fazer os testes, podem ser utilizados os manequins antropométricos que são ferramentas de projeto funcionais e relevantes na atividade projetual. Do mesmo modo que os gabaritos que representam elementos de máquinas em escala e são úteis ao engenheiro, os manequins antropométricos são de vital importância para avaliar a relação dimensional da interface homem-máquina. Seja em 
uma situação existente no momento projetual ou na validação de propostas, os manequins antropométricos oferecem outputs para otimização dos projetos. Os manequins podem ser construídos de diversos materiais como em acetato ou acrílico para o uso no departamento de projeto (MORAES, 2001).

Segundo Pazmino et al., (2006) o manequim é uma ferramenta paramétrica de auxílio ao projetista durante o desenvolvimento do produto podendo ser utilizada nas diversas fases do desenvolvimento. O manequim é utilizado para auxiliar no dimensionamento do produto, informando dados próximos ao usuário. A figura 2 exemplifica o manequim usado de forma integrada ao ambiente CAD para geração de um esboço na fase de conceitual do produto, levando-se em conta algumas dimensões básicas.

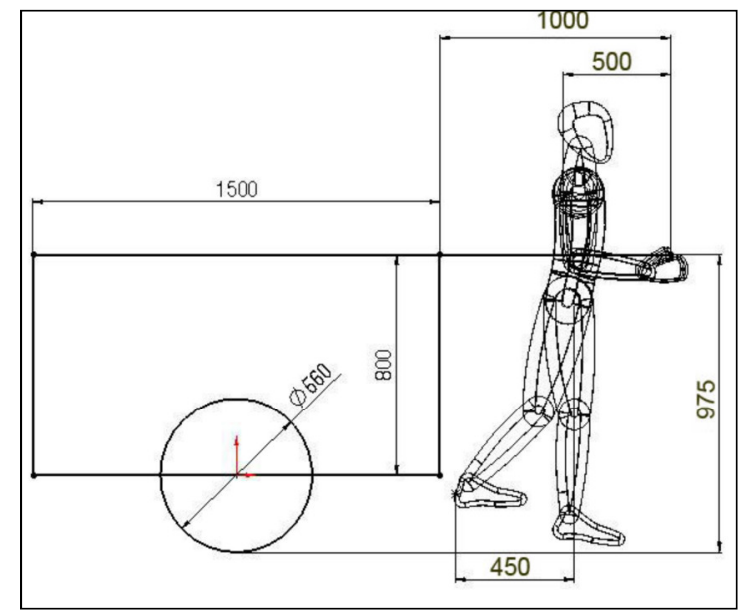

Figura 2 - Manequim antropométrico na fase conceitual Fonte: Pazmino et al., 2006

Para Zhang et al., (2010) uma desvantagem da antropometria tradicional é que ela pode oferecer aos projetistas apenas uma dimensão ou duas dimensões de dados, limitações que os impede de entender e estudar as formas anatômicas do corpo humano no espaço em três dimensões. Como mencionado, a fim de proporcionar um melhor apoio para o projetista na medição e modelagem do corpo humano, temos que considerar a antropometria 3D.

Segundo Guimarães (2006) existem inúmeros softwares que simulam manequins antropométricos. São programas que dispõem de várias opções para controlar a antropometria do modelo humano. Este modelo é construído a partir da ligação com dimensões que representam os membros do corpo humano e cada ponto de ligação representa uma articulação com um segmento adjacente.

Esses tipos de ferramentas são aplicados no projeto, na modificação, na visualização e análise dos recursos humanos, layout de trabalho e / ou interações do produto. O manequim ergonômico na fabricação de ferramentas de modelagem é usado principalmente para visualizações. Estas são frequentemente utilizadas para fornecer informações sobre o corpo, postura, acessibilidade, campo de visão e verificar o alcance dos braços, mãos e ferramentas, e servem como base para o designer avaliar e tomar decisões (LÄMKULL et al., 2007). 


\subsection{Prototipagem}

Segundo Domingues (2011) A palavra "protótipo" passou por um processo histórico de flexibilização conceitual, já que começou a ser utilizada para descrever qualquer versão de um objeto que ainda será produzido, dos mais simples esboços ao modelo mais fidedigno. Dessa forma, neste artigo define-se protótipo como qualquer modelo de um objeto antes que ele seja produzido.

Os modelos e protótipos são úteis para que os designers possam discutir a ideia com stakeholders; são dispositivos que facilitam a comunicação entre os membros das equipes e que permitem uma forma eficaz de testar produtos. Para Brown (2010), a transição do físico ao abstrato e de volta ao físico é um dos processos mais fundamentais por meio dos quais o designer explora o universo, libera a imaginação e abre a mente para novas possibilidades. Já para Pupo (2009) a passagem do físico ao digital e vice-versa tem sido uma forma interativa e rápida de se obter informações importantes para as decisões projetuais. O modelo físico auxilia a mente para a imaginação, abastecendo o designer de novas ideias, novas ferramentas e um maior controle durante o processo de projeto. Certamente, ao invés de fugir da realidade, a utilização do modelo físico trabalha a agilidade técnica e a sensibilidade material em uma conexão prazerosa entre arte, ciência, design, tecnologia e prática projetual (PUPO, 2009).

No processo de projeto da concepção do produto, a antecipação do seu uso auxilia a identificar possíveis problemas relacionados à interação homem-produto. Porém, no início das fases de concepção do produto pode-se utilizar de diversas ferramentas para torná-lo iterativo. Deve-se salientar que, as técnicas de modelação podem ir desde os esboços rápidos até aos protótipos funcionais. A sua escolha depende, sobretudo, dos objetivos de cada fase, das verbas, dos tempos disponíveis e dos usuários para fazer os testes. Cada uma delas tem as suas vantagens e desvantagens, assim como o seu momento apropriado de uso.

O mock-up é normalmente construído em escala 1:1 e com materiais de baixo custo e grande flexibilidade, de forma a proporcionar meios para alterações rápidas. Conforme Neto e Santos (2002), em relação à ergonomia, para conseguir os resultados nos testes estáticos e dinâmicos, é fundamental a construção dos mock-ups na escala 1:1, permitindo uma avaliação bastante próxima da realidade e, principalmente, pelo fato de poderem ser utilizados com "pessoas reais" na realização dos testes, o que confere ao experimento um nível de credibilidade maior do que em simulações virtuais, inclusive por permitir avaliar aspectos como níveis de conforto e, em algumas situações, o próprio comportamento e experiência dos usuários.

Em uma abordagem de projeto centrada no usuário e iterativa, os protótipos ou modelos devem estar disponíveis em uma forma que possa ser avaliada com os usuários. A prototipação é utilizada a fim de evitar possíveis desentendimentos com o usuário e testar a viabilidade técnica de um produto.

O protótipo é uma versão limitada do produto com o intuito de responder a questões específicas sobre a usabilidade ou adequação do produto aos requisitos de projeto. Protótipos dão suporte aos designers para escolha de uma, entre várias opções. E para perceber a funcionalidade, o tamanho, usabilidade, etc.

Para Preece et al., (2005) os protótipos proporcionam uma impressão acerca da experiência do usuário já que permitem interagir e explorar a sua conveniência. Segundo a autora, existem diferentes tipos de protótipos adequados para estágios 
diferentes de desenvolvimento e para oferecer diferentes tipos de informações. Por exemplo, testar a viabilidade técnica de uma ideia, esclarecer alguns requisitos vagos, realizar alguns testes com os usuários, verificar as dimensões.

Segundo PREECE et al., (2005) um protótipo de baixa-fidelidade é aquele que não se assemelha muito ao produto final, utiliza materiais muito diferentes da versão final definida. São modelos em que os materiais simulam os reais, uma impressora feita de papelão, um celular de madeira ou poliuretano (PU). Os protótipos de baixa fidelidade são úteis porque são simples, baratos e de rápida confecção, sendo fácil ser modificados permitindo suporte à exploração de ideias e novas alternativas de solução em aspectos específicos como: tamanho, forma etc.

PREECE et al. (2005) recomenda o modelo de baixa fidelidade ser utilizado na fase de projeto conceitual ou nas fases iniciais do projeto. Deve ser rápido para ser construído, rudimentar e de baixo custo usando papelão, madeira, reutilização de peças, cola, entre outros, sendo utilizados como um meio exploratório para comunicar, informar, sensibilizar etc. A figura 3 mostra mock-up em PU e em papelão.
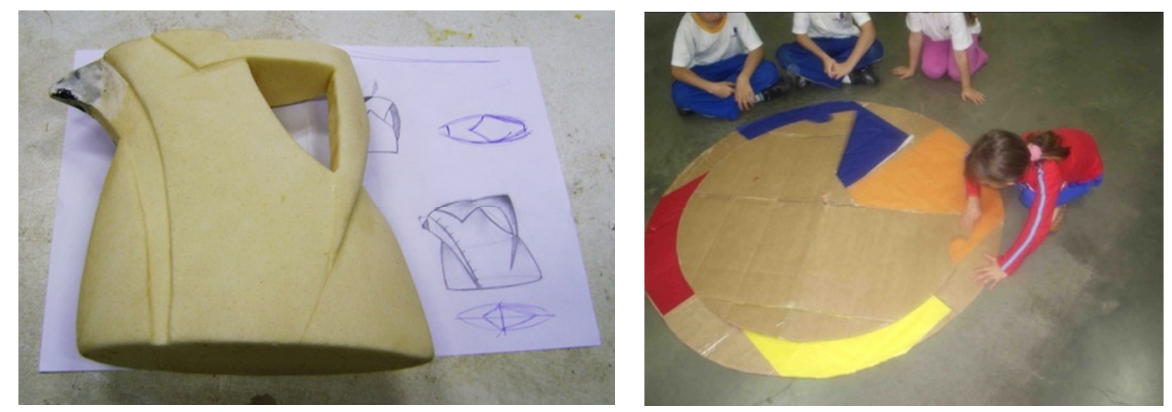

Figura 3- Mock-up de chaleira e de brinquedo infantil

Fonte: Medeiros (2010); Preuss (2007)

O protótipo de média fidelidade demanda maior atenção no acabamento eliminando bordas mal acabadas ou detalhes não resolvidos, utiliza materiais de melhor qualidade e similares ao do produto final em cores, texturas, algumas funções, e na dimensão 1:1. Permite maior tipo de interação com o usuário; levam um tempo razoável de materialização, e tem um custo médio de fabricação.

Protótipo de alta-fidelidade utiliza materiais que estarão no produto final, similar ao produto acabado. Alguns problemas são que levam muito tempo para serem construídos e os designers relutam em mudar algo no qual trabalharam de forma artesanal durante horas. Segundo Brown (2010) quanto maiores forem a complexidade e o custo, mais "acabado" ele pode aparentar e menos chances os designers terão de se beneficiar de um feedback construtivo. Este protótipo é útil para vender ideias a pessoas e para validar questões técnicas e funções. A figura 4 mostra um protótipo de alta-fidelidade. 


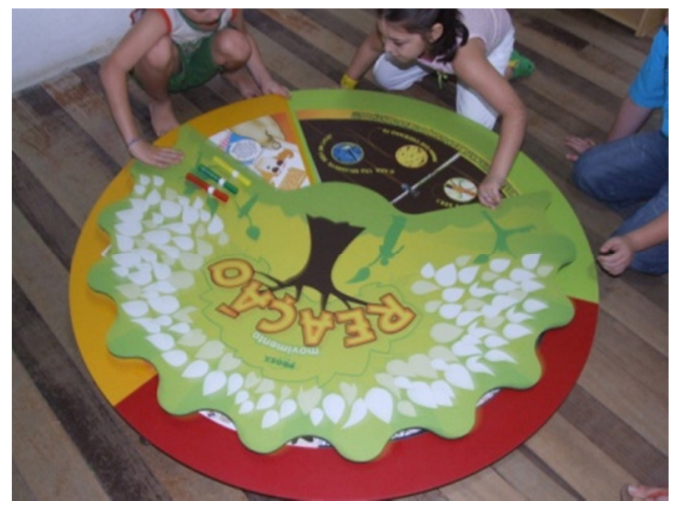

Figura 4 - Protótipo de alta-fidelidade de brinquedo infantil Fonte: Preuss (2007)

Segundo (Tullis, 1990 apud Alcoforado, 2007) a fidelidade do protótipo é julgada pela aparência como ele é percebido pelas pessoas, ou seja, trata-se dos aspectos tangíveis como a estética, acabamento e aparência.

O quadro 1 mostra a eficácia de protótipos de baixa, média e de alta complexidade baseada em (RUDD et al., 1996 apud PREECE et al., 2005).

Quadro 1 - Vantagens e Desvantagens de protótipos de diversas complexidades

\begin{tabular}{|l|l|l|}
\hline TIPO & VANTAGENS & DESVANTAGENS \\
\hline Protótipo de & - Custo baixo de desenvolvimento; & - Verificação limitada de \\
& - Permite avaliar vários conceitos & erros. \\
& de design (forma, dimensão, & - Especificação pobre em \\
& estética etc.); & detalhes para uso. \\
& - Instrumento de comunicação & - Uso ou entendimento \\
& para a equipe de projeto e & conduzido pelo facilitador \\
& usuário; & - Utilidade limitada após a \\
- Útil para identificação de & fase conceitual \\
& necessidades do usuário e do & - Utilidade limitada para \\
& mercado; & testes de usabilidade \\
& - Proof-of-concept (demonstrações & - Limitações de forma, \\
& que o conceito ou ideia & estética, cores, texturas, \\
& funciona); & funções. \\
\hline Protótipo de & - Custo aceitável & - Demanda custo e tempo \\
média & - Permite avaliar algumas funções & - Participação na equipe de \\
fidelidade & - Uso conduzido pelo usuário & alguém com capacidade de \\
& - Ferramenta para comunicação & materializar \\
& com o usuário e equipe de & - Uso de tecnologias como \\
& projeto & corte a laser, impressora \\
& - Eliminação de detalhes mal & 3D. \\
& solucionados & \\
\hline
\end{tabular}

Fonte: Elaborado pelos autores da pesquisa baseada em (RUDD et al., 1996 apud PREECE et al., 2005;) 
Quadro 1 - Vantagens e Desvantagens de protótipos de diversas complexidades (continuação)

\begin{tabular}{|l|l|l|}
\hline TIPO & VANTAGENS & DESVANTAGENS \\
\hline Protótipo de & - Funcionalidade completa & - Desenvolvimento caro. \\
alta-fidelidade & - Totalmente interativo & - Sua criação demanda \\
& - Uso conduzido pelo usuário & tempo e expertise do \\
& - Define claramente a função & - Ineficiente para designs \\
& - Aplicação para uso e teste & Proof-of-concept \\
& - Mesmo look and feel que o & - Uso de Tecnologias diversas \\
& - Sroduto final & - Bloqueia a percepção de \\
& - Ferramenta para comunicação & $\begin{array}{l}\text { problemas por parte da } \\
\text { equipe de projeto }\end{array}$ \\
& - Fem o usuário e o cliente & \\
& com o marketing & \\
\hline Modelo de & - Ferramenta para comunicação & - Desenvolvimento caro. \\
apresentação & com o marketing e o cliente. & - Sua criação demanda \\
& & tempo e expertise do \\
& & construtor \\
& & - Uso de tecnologias de alto \\
& & custo. \\
\hline
\end{tabular}

Fonte: Elaborado pelos autores da pesquisa baseada em (RUDD et al., 1996 apud PREECE et al., 2005;)

Schrage (1996 apud PREECE et al. 2005) menciona que existem basicamente dois tipos de cultura organizacional para inovações, a cultura de especificação e prototipação. Na primeira, novos produtos e desenvolvimentos são dirigidos por especificações escritas, ou seja, um conjunto de requisitos de projeto. Na segunda, entender os requisitos e desenvolver são atividades dirigidas pela prototipação. Ambas as abordagens têm vantagens e desvantagens, a primeira uma especificação cuidadosamente preparada pode ser completamente inviável quando se inicia a prototipação. Da mesma forma, um protótipo de alta qualidade pode resultar muito caro quando produzido em grande escala.

Considerando a importância da aplicação da prototipagem no processo de design, a seguir, no Quadro 2, é mostrada uma relação dos níveis de fidelidade dos protótipos e manequins antropométricos com as fases do processo de design, tipos adequados a cada uma das fases e materiais. Nele, a prototipagem rápida é considerada em várias fases do projeto, cabendo salientar que é uma tecnologia que está em crescimento com tendências a redução de custos. 
Quadro 2 - Relação entre os níveis de fidelidade com fases do processo

\begin{tabular}{|c|c|c|c|}
\hline $\begin{array}{c}\text { NÍVEL DE } \\
\text { FIDELIFADE }\end{array}$ & $\begin{array}{c}\text { FASE DO } \\
\text { PROCESSO }\end{array}$ & TIPOS & MATERIAIS \\
\hline $\begin{array}{l}\text { Baixa } \\
\text { fidelidade }\end{array}$ & $\begin{array}{l}\text { - Projeto } \\
\text { informacional } \\
\text { - Projeto } \\
\text { conceitual }\end{array}$ & $\begin{array}{l}\text { - Sketch } \\
\text { - Story board } \\
\text { - Mock-up 1:1 } \\
\text { - Manequim } \\
\text { bidimensional em } \\
\text { escala } \\
\text { - Manequim } \\
\text { virtual }\end{array}$ & $\begin{array}{l}\text { - Papel/ Papelão } \\
\text { - Fitas adesivas } \\
\text { - Cola } \\
\text { - Clay } \\
\text { - Poliuretano PU } \\
\text { - Arame } \\
\text { - Reuso de materiais } \\
\text { - Madeira } \\
\text { - Corte a laser } \\
\text { - Prototipagem digital }\end{array}$ \\
\hline $\begin{array}{l}\text { Média } \\
\text { fidelidade }\end{array}$ & $\begin{array}{l}\text { - Projeto } \\
\text { conceitual } \\
\text { - Projeto } \\
\text { preliminar }\end{array}$ & $\begin{array}{l}\text { - Rendering } \\
\text { - Modelo virtual } \\
\text { - Modelo físico } \\
\text { - Ambientação } \\
\text { - Manequim } \\
\text { virtual } \\
\text { - Manequim físico } \\
\text { em escala }\end{array}$ & $\begin{array}{l}\text { - Madeira } \\
\text { - Poliuretano PU } \\
\text { - Clay } \\
\text { - Reuso de peças e } \\
\text { componentes } \\
\text { - Silicone } \\
\text { - Tintas } \\
\text { - Massa plástica } \\
\text { - Corte a laser } \\
\text { - Prototipagem digital }\end{array}$ \\
\hline $\begin{array}{l}\text { Alta } \\
\text { fidelidade }\end{array}$ & $\begin{array}{l}\text { Projeto } \\
\text { detalhado e de } \\
\text { produção }\end{array}$ & $\begin{array}{l}\text { - Modelo real 1:1 } \\
\text { - Sistemas } \\
\text { mecânicos e } \\
\text { elétricos }\end{array}$ & $\begin{array}{l}\text { - Corte a laser } \\
\text { - Prototipagem digital } \\
\text { - Reuso de produtos, peças e } \\
\text { componentes. } \\
\text { - Componentes mecânicos e } \\
\text { elétricos }\end{array}$ \\
\hline $\begin{array}{l}\text { Modelo de } \\
\text { apresentação }\end{array}$ & $\begin{array}{l}\text { Projeto } \\
\text { detalhado e de } \\
\text { produção }\end{array}$ & $\begin{array}{l}\text { - Modelo em } \\
\text { escala reduzida } \\
\text { 1:4 ou tamanho } \\
\text { real 1:1 }\end{array}$ & $\begin{array}{l}\text { - Madeira } \\
\text { - Poliuretano PU } \\
\text { - Reuso de peças e } \\
\text { componentes } \\
\text { - Acabamentos (pintura) }\end{array}$ \\
\hline
\end{tabular}

Fonte: Adaptado de Alcoforado, 2007 p. 178

Os materiais mencionados são os básicos, porém existe uma diversidade e seu uso vai depender do custo estabelecido no projeto.

\subsection{Integração dos processos}

De acordo com Volpato et al., (2007) o processo de desenvolvimento de produto apresenta uma natureza multi e interdisciplinar e os modelos físicos tridimensionais contribuem neste processo. Apesar do interesse crescente em simulações tridimensionais virtuais de produtos, obtidas com computação gráfica, algumas sensações como textura, segurança, manuseio, aroma e percepção formal 
somente são compreendidas com modelos físicos tridimensionais, razão pelo qual modelos e protótipos são elementos importantes para o desenvolvimento de produto.

Pode-se citar como uma dessas ferramentas, segundo MIETTI E VENDRAMETO, (2000), a prototipagem rápida, associada ao CAD, que reduz o tempo de produção de modelos e protótipos nas fases de projeto, testes e atividades de pré-produção, estreitando o tempo de fabricação de ferramental. Este processo e ferramenta contribuem expressivamente nos requisitos de produtividade e ainda possibilitando a redução de custos. Existem inúmeras aplicações da prototipagem rápida: visualização e/ou correção do Design, protótipos de apresentação, análise de aspectos ergonômicos, protótipos funcionais, fabricação rápida de ferramentas e manufatura de pequenas e médias séries. É possível a produção de modelos físicos tridimensionais em diversos tipos de materiais, como polímeros, cerâmicos, metais, madeira, entre outros.

\section{Atividade prática}

Este item exemplifica a integração de maneira didática apresentando os resultados preliminares da aplicabilidade da prototipagem digital, manequins antropométricos e modelos em escalas reduzidas.

Para a realização desta pesquisa foi desenhado em software de modelagem 3D a proposta de um veículo ultra compacto. Com este arquivo tridimensional foi exportado para o formato "STL", possibilitando a importação no software 123DMake, da Autodesk, capaz de produzir de forma intuitiva a configuração de planos interligados posteriormente cortados em cortadora Laser. Na figura 5 apresenta-se 0 resultado utilizado para fazer o arquivo de corte.

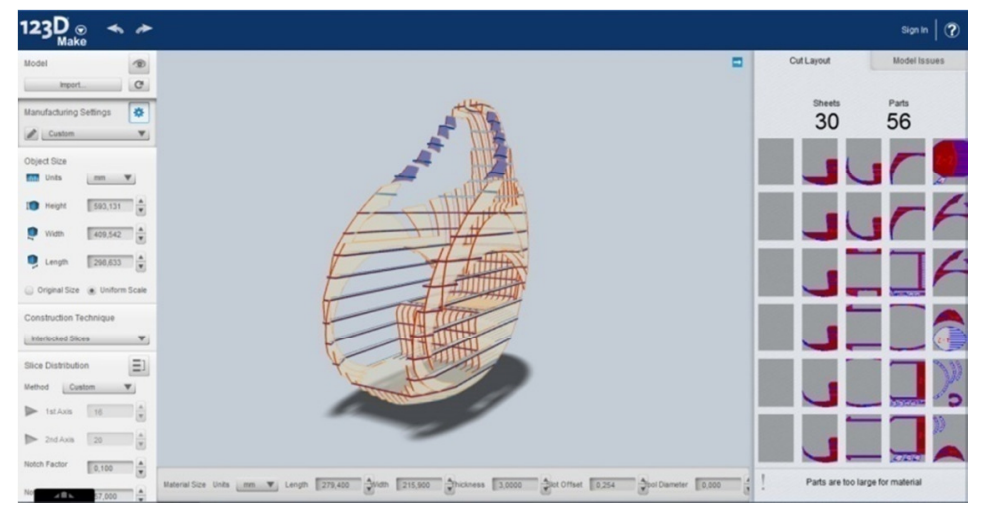

Figura 5 - Solução de corte

Fonte: Elaborado pelos autores da pesquisa

Para demonstrar a aplicabilidade da ferramenta é ilustrado nas Figuras 6 e 7 uma amostra das variações possíveis de realizar para encontrar as soluções desejadas. A figura 6 apresenta a alteração no ângulo dos planos verticais transformados em posicionamentos radiais. 


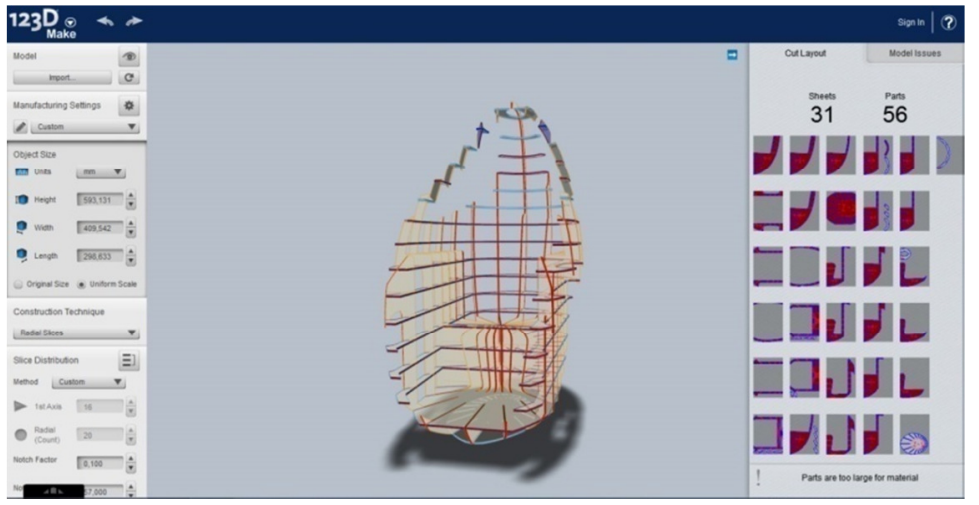

Figura 6 - Solução de corte 2

Fonte: Elaborado pelos autores da pesquisa

Já a Figura 7 apresenta uma quantidade maior de planos tanto no eixo vertical quanto no horizontal, possibilitando ao usuário selecionar a configuração de seu interesse.

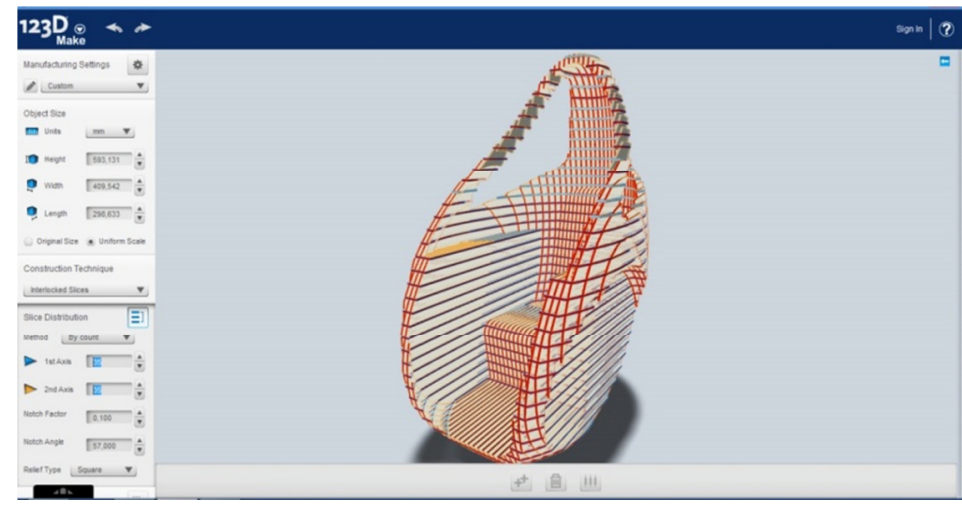

Figura 7 - Solução de corte 3

Fonte: Elaborado pelos autores da pesquisa

$\mathrm{Na}$ etapa seguinte foi realizado o corte na cortadora Laser e posteriormente montado como ilustra a Figura 8.

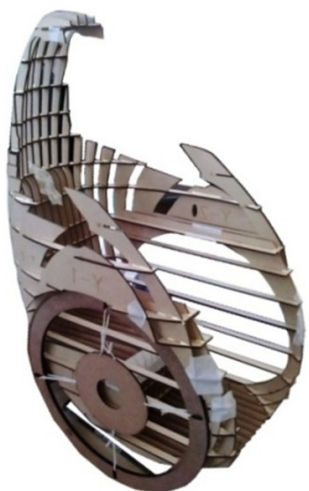

Figura 8 - Modelo cortado e montado Fonte: Elaborado pelos autores da pesquisa 
Na próxima fase foi utilizado papel e cola para montar a superfície e possibilitar a adição de massa plástica (Figura 9).

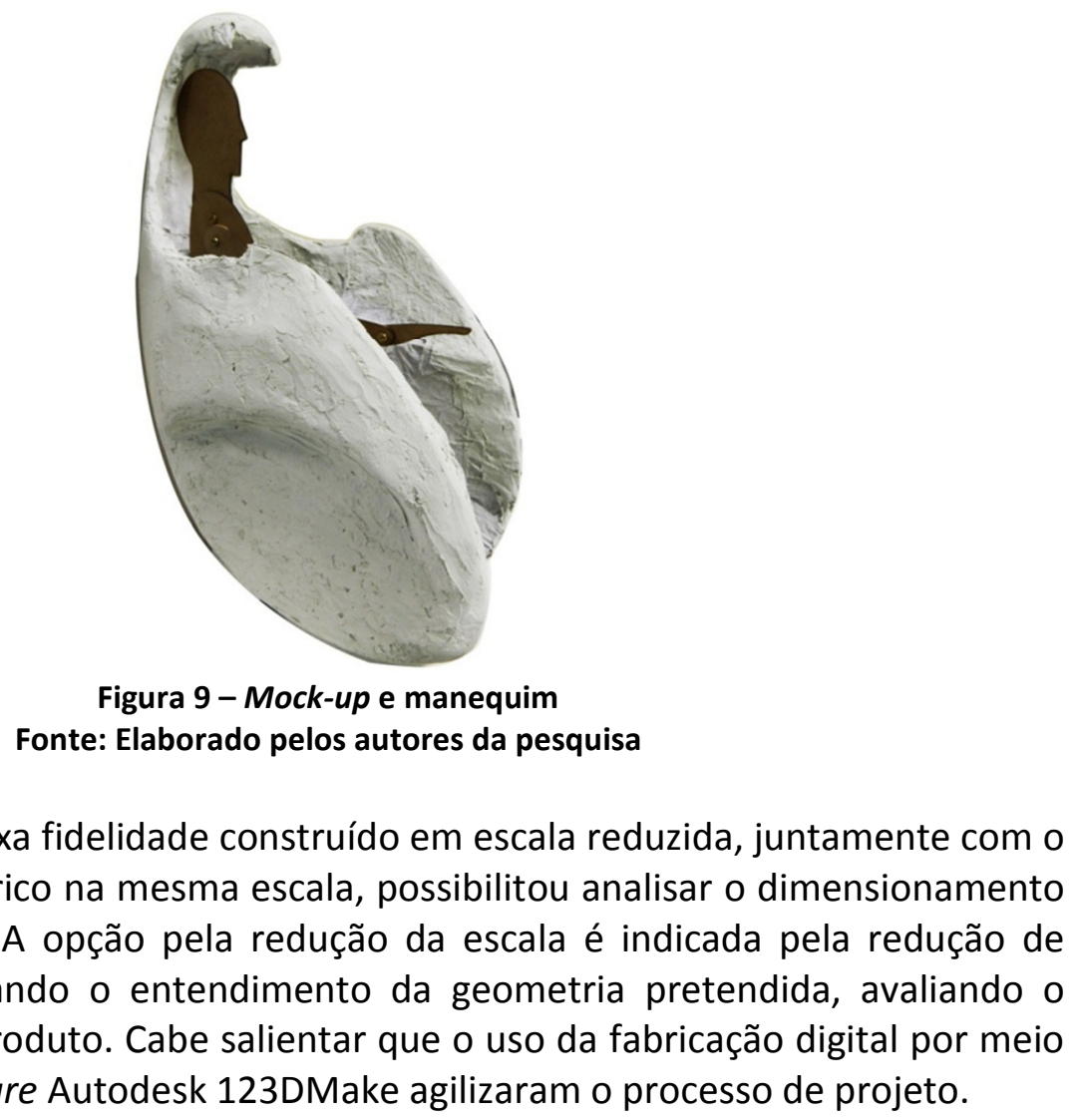

\section{CONCLUSÃO}

O processo de design iterativo envolve testar, avaliar e aperfeiçoar em um círculo contínuo. A prototipagem permite que o modelo de baixa e media fidelidade sejam testados e analisados pela equipe de desenvolvimento e pelos usuários. $\mathrm{O}$ artigo mostrou que a prototipagem proporciona novas ideias, dessa forma, pode ser utilizada desde o início da fase de concepção de um produto, auxiliando para que a equipe não se fixe às ideias e que se minimizem os erros.

No ensino de design os protótipos de diversas complexidades geralmente são feitos pelos alunos na fase final dos projetos, atuando como simples modelos de apresentação. Nesse caso, o modelo é subutilizado já que no final do processo apenas serve para mostrar a ideia concreta. Sendo que, a maior vantagem do uso dos protótipos é proporcionarem informações à equipe de design para aperfeiçoar o desenvolvimento pelo surgimento de insights e novas ideias. Acredita-se que com o auxílio das novas tecnologias, como a prototipagem rápida, os protótipos de baixa e média complexidade possam ser construídos e mais utilizados devido à redução de tempo e custo na confecção dos modelos.

\section{REFERÊNCIAS}

ALCOFORADO, Manoel Guedes. Comunicação intermediada por protótipos. In: Dissertação de Mestrado da Universidade Federal de Pernambuco. Recife, 2007. 
BROWN, Tim. Design Thinking: uma metodologia poderosa para decretar o fim das velhas ideias. Editora Campus: Rio de Janeiro, 2010.

DOMINGUES, Delmar Galisi. Protótipos para a criação de jogos digitais: Aplicação no ensino de design de games. In: Tese de doutorado de design da PUC-Rio. Rio de Janeiro. 2011.

GUIMARÃES, L. B. de M. Ergonomia de Produto (2) (5 ed.). 5. ed. Porto Alegre: FEENG, 2006.

LÄMKULL, D., Hanson, L., Örtengren R., 2007. The Influence of Virtual Human Model Appearance on Visual Ergonomics Posture Evaluation. Applied Ergonomics, Volume 38, Issue6, pp. 713-722

LAUREL, Brenda. Design Research: Methods and perspectives. MIT Press. 2003.

MIETTI, M. A. VENDRAMETO, O. Uso de prototipagem rápida como fator de competitividade. In: Encontro Nacional de Engenharia de Produção 20. APEBRO. São Paulo. 2000.

MEDEIROS, Ivan. Apostila da disciplina de modelos. Univille. 2010

MORAES, Ana Maria de (Organizador). Ergodesign: produtos e processos. Rio de Janeiro: 2AB, 2001.

NETO, Pedro Luiz de Oliveira Costa, e Carlos Maurício Duque dos SANTOS. "Aspectos Ergonômicos e Estatísticos no Projeto de um Carro Do Metrô."Gestão e Produção vol.9, n.1 (2002): p. 93-105.

PAZMINO, Ana Verónica; LAUFER, Adriana; WEBER, Cláudio. Aplicação de um manequim antropométrico como ferramenta de auxílio no desenvolvimento de carrinho de coleta de materiais recicláveis. In: 60 CONGRESSO INTERNACIONAL DE ERGONOMIA E USABILIDADE, 2006, Bauru. Anais do 6ergodesign, 2006.

PREECE, Jennifer; ROGERS, Yvonne; SHARP, Helen. Design de interação: além da interação homem computador. Porto Alegre: Bookman, 2005.

PREUSS, Jenifer M. A mídia como ferramenta de sensibilização do processo de Reciclagem artesanal da embalagem longa vida. Trabalho de Conclusão de Curso de Design. Univille. Joinville. 2007.

PUPO, R. Inserção da PROTOTIPAGEM e FABRICAÇÃO DIGITAIS no processo de projeto: um novo desafio para o ensino de arquitetura. 2009. 259 f. Tese (doutorado) Universidade Estadual de Campinas, Faculdade de Engenharia Civil, Arquitetura e Urbanismo.

SAUER, J. et al., The influence of user expertise and prototype fidelity in usability tests. Applied Ergonomics 41 (2010) 130-140.

VOLPATO, N., et al., Prototipagem Rápida - Tecnologia s e Aplicações. Edgar Blucher, São Paulo, 2007.

ZHANG, B., I. HORVÁTH, J.F.M. MOLENBROEK, E C. SNIJDERS. "Using artificial neural networks for human body posture prediction." International Journal of Industrial Ergonomics, n. 40 (2010): p.414-424 